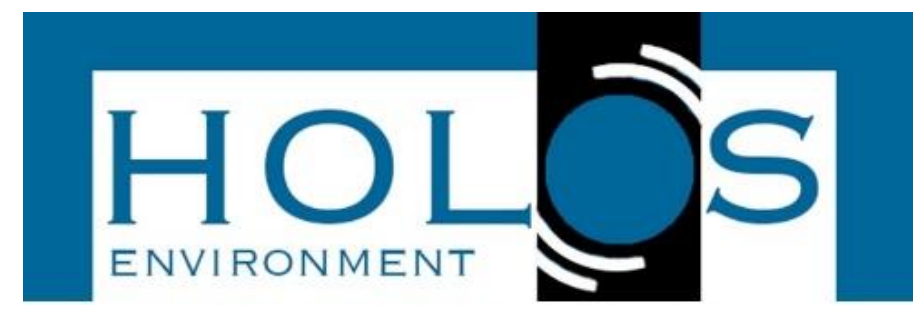

\title{
BALANÇO DE MASSA DE BIODIGESTOR MODELO BIOKÖHLER ABASTECIDO COM DEJETOS DE BOVINOCULTURA DE LEITE
}

\section{BIOKÖHLER MODEL BIODIGESTER MASS BALANCE SUPPLIED WITH DAIRY CATTLE MANURE}

\author{
Caroline Monique Tietz Soares ${ }^{1}$; Armin Feiden ${ }^{1}$
}

Artigo recebido em: 24/04/2019 e aceito para publicação em: 16/06/2019.

DOI: http://dx.doi.org/10.14295/holos.v19i3.12337

Resumo: As transformações dos sistemas de produção de animais têm originado avanços significativos ao setor. Entretanto, tais transformações têm provocado problemas ambientais, em razão da concentração e aumento de escala da atividade. Diante deste cenário, é de fundamentalmente importante a busca por novas alternativas para mitigar os problemas ambientais e também agregar valor aos resíduos gerados. Estudos voltados para a geração e o aproveitamento do biogás a partir desses resíduos tem ganhado cada dia mais relevância, mostrando-se como uma alternativa interessante. Este estudo teve como objetivo verificar o balanço de massa de um biodigestor modelo Bioköhler abastecido com dejetos de bovinocultura de leite. O experimento foi realizado em um biodigestor de $20 \mathrm{~m}^{3}$ localizado na Estação Experimental Antônio Carlos dos Santos Pessoa, pertencente à UNIOESTE - Campus de Marechal Cândido Rondon, no período de 03/08/2014 a 07/02/2015. Foram obtidos dados de densidade dos afluentes e efluentes, valores de sólidos totais, fixos e voláteis, volume de biogás produzido e teor de metano presente neste biogás. Os resultados indicaram que a capacidade média esperada de produção de biogás esteve em torno de $12 \mathrm{~m}^{3}$ por dia e obteve-se uma média de $57,33 \%$ de metano neste biogás. Houve remoção de sólidos voláteis e esta foi satisfatória.

Palavras-chave: Digestão anaeróbia. Biogás. Metano.

Abstract: The transformations of animal production systems have led to significant advances in the sector. However, these transformations have also produced environmental problems, due to the concentration and scale of activity. Therefore, it is of fundamental importance to explore new alternatives to mitigate the problem and also to add value to the generated waste. Studies aimed at the generation and use of biogas from these wastes have increasingly gained visibility, proving to be an interesting alternative. The objective of this study was to verify the mass balance of a Bioköhler biodigestor model supplied with bovine milk manure. The experiment was carried out in a $20 \mathrm{~m}^{3}$ biodigestor located at the Experimental Station Antonio Carlos dos Santos Pessoa, belonging to UNIOESTE - Campus of Marechal Cândido Rondon, from 08/03/2014 to 07/02/2015. Density data were obtained of the tributaries and effluents, total, fixed and volatile solids values, volume of biogas produced and methane content present in this biogas. The results indicated that the expected average capacity of biogas production was around $12 \mathrm{~m}^{3}$ per day and an average of $57.33 \%$ of methane was obtained in this biogas. There was removal of volatile solids and this was satisfactory.

Keywords: Anaerobic digestion. Biogas. Methane.

\footnotetext{
${ }^{1}$ Universidade Estadual do Oeste do Paraná (Unioeste), Marechal Cândido Rondon, PR. E-mail: (carol.tietz@hotmail.com,armin.feiden@gmail.com)
} 


\section{INTRODUÇÃO}

O desenvolvimento de técnicas de produção agropecuária cada vez mais modernas possibilitam um aumento na eficiência das cadeias produtivas de alimentos. Por meio do uso dessas tecnologias é possível reduzir a área de confinamento de animais, bem como diminuir a quantidade de trabalhadores necessários à produção agrícola. Entretanto, esse sistema intensivo de produção, cujas criações se dão em caráter de confinamento, gera resíduos com alta capacidade de poluição, os quais podem ocasionar danos ao meio ambiente, aos animais e ao homem. Diante disto, é de fundamental importância que estes sejam tratados de forma adequada (ASSENHEIMER, 2007).

Dentre os resíduos agropecuários, o da bovinocultura merece destaque, tendo em vista que o rebanho bovino brasileiro é um dos maiores do mundo. Segundo dados de 2017 do Instituto Brasileiro de Geografia e Estatística - IBGE, o efetivo nacional de bovinos em 2016 chegou a 218,2 milhões de cabeças, com maiores concentrações no Centro-Oeste, que reuniu $34,4 \%$ do rebanho nacional, com destaque para o Mato Grosso, com 30,3 milhões de cabeças (13,9\% do total). Minas Gerais, Goiás e Mato Grosso do Sul representaram, respectivamente, 10,8\%, 10,5\% e $10,0 \%$ do efetivo nacional.

$\mathrm{Na}$ produção de leite, o Brasil ocupa a quinta posição no ranking mundial, segundo pesquisas do Centro de Estudos Avançados em Economia Aplicada - Cepea, da Esalq/USP $(2016,2018)$.

A digestão anaeróbia é um dos processos existentes para o tratamento desses resíduos. Constitui-se em um método no qual os compostos orgânicos dos dejetos podem ser convertidos em biogás e biofertilizante, por meio da ação de microrganismos especializados em biodigestores (PECORA et al., 2008; SOUZA; CAMPOS, 2007).

O biogás é composto por uma mistura variada de gases e dentre eles faz-se presente em maior quantidade o metano $\left(\mathrm{CH}_{4}\right)$ e o dióxido de carbono $\left(\mathrm{CO}_{2}\right)$, podendo chegar a conter entre $40 \%$ a $75 \%$ e $25 \%$ a $40 \%$, respectivamente, dependendo da eficiência do processo (FARIA, 2012).

Isto posto, o objetivo desse estudo foi realizar o balanço de massa de um biodigestor modelo Bioköhler abastecido com dejetos de bovinocultura de leite, quantificar e estudar o biogás produzido, bem como o teor de $\mathrm{CH}_{4}$ presente. 


\section{MATERIAL E MÉTODOS}

A pesquisa foi realizada no período de 03 de agosto de 2014 a 07 de fevereiro de 2015 na Estação Experimental Prof. Dr. Antonio Carlos dos Santos Pessoa - Linha Guará do município de Marechal Cândido Rondon - PR, pertencente a Universidade Estadual do Oeste do Paraná - Campus de Marechal Cândido Rondon.

A análise dos resultados obtidos foi feita a partir do agrupamento dos dados relativos a períodos de três semanas, formando 9 tratamentos. A determinação desta concentração foi feita a fim de facilitar a manipulação e exposição dos dados.

O biodigestor experimental presente na estação era da marca Bioköhler, com câmara de biodigestão em fibra de vidro, formada pela união de duas caixas d'água de $10.000 \mathrm{~L}$ cada, sendo uma caixa d'água normal e a outra tendo o seu fundo arredondado, contendo uma saída para manutenção, permitindo a abertura da mesma em caso de necessidade. Ambas as caixas possuíam material reforçado em função da pressão hidráulica do líquido e do gás. A câmara de biodigestão detinha capacidade de $20 \mathrm{~m}^{3}$, com volume útil de $19,56 \mathrm{~m}^{3}$, estava instalada no sentido vertical, possuindo sistema de alimentação contínuo.

Uma das extremidades da câmara de biodigestão, a inferior (referente à porção de uma caixa d'água) era totalmente enterrada e a outra extremidade, a qual possuía o fundo arredondado, ficava fora do solo. A canalização de afluente e biogás era toda subterrânea para proteção do sol, chuva e possíveis impactos que poderiam danificá-la.

O dejeto bovino era raspado do estábulo presente na estação e acumulado no início do encanamento, onde era misturado com água e a mistura resultante escoava por dentro do encanamento e se deslocava por gravidade até a caixa de alimentação do biodigestor. Este deslocamento ocorria por diferença hidráulica, visto que a mistura era feita de forma a manter uma concentração de sólidos totais entre $8 \mathrm{e}$ $12 \%$, que naturalmente é fluida e se comporta como um líquido (CASTRO; CORTEZ, 1998).

Após ser encaminhada para a caixa de alimentação, a mistura de água e dejetos era quantificada através da aferição da altura atingida pela solução. Posteriormente, promovia-se a coleta da amostra do afluente do biodigestor. O biodigestor então era alimentado por esta mistura de água e dejetos bovinos provenientes da 
própria estação, os quais eram alimentados com feno, ração e silagem. As vacas permaneciam no estábulo por aproximadamente 4 horas.

Sendo o biodigestor em estudo de sistema contínuo, a mesma quantidade de carga diária de matéria orgânica que nele entrava saía na forma de biofertilizante, o que permitia a realização da segunda coleta do material (efluente).

Terminado a alimentação do biodigestor realizava-se a segunda medida da altura da mistura presente na caixa de alimentação, sendo que esta a bomba não conseguia succionar. Após as aferições realizava-se o cálculo do volume de entrada a partir da Equação 1:

$\mathrm{V}=\pi \cdot \mathrm{r}^{2} \cdot \mathrm{p}$

em que:

$\mathrm{V}=$ volume;

$\Pi=p i$; proporção numérica que tem origem na relação entre o perímetro de uma circunferência e seu diâmetro, tendo valor aproximado de 3,14;

$r=$ raio, a caixa de entrada tem diâmetro de $1 \mathrm{~m}$, sendo o raio de $0,5 \mathrm{~m}$, logo, $\mathrm{r}^{2}=$ 0,25 ;

$\mathrm{p}=$ profundidade, diferença entre as medidas da caixa de entrada antes e depois de o biodigestor ser alimentado.

As coletas das amostras para efetuar as análises foram realizadas semanalmente, geralmente nas quintas-feiras, totalizando 54 amostras, sendo 27 de afluentes e 27 de efluentes. As amostras foram acondicionadas em garrafas PET de 500 $\mathrm{mL}$ e armazenadas em congelador para posterior análise.

A operação e o manejo do biodigestor eram realizados diariamente no período da tarde. O Tempo de Detenção Hidráulica - TDH calculado foi de 50 dias. O experimento consistiu no monitoramento das variáveis: densidade dos afluentes e efluentes, valores de sólidos totais (ST), fixos e voláteis (SV), volume de biogás produzido e teor de $\mathrm{CH}_{4}$ presente no biogás.

A densidade dos afluentes e efluentes foi analisada com o uso de um densímetro para massa específica da marca Incoterm, modelo número 5582, de escala 1,000 a $1,100 \mathrm{~g} / \mathrm{mL}$, aferido a $20{ }^{\circ} \mathrm{C}$. 
Os sólidos totais, fixos e voláteis foram calculados para o afluente e efluente, podendo-se calcular então os valores de carga orgânica, rendimento de biogás por $\mathrm{m}^{3}$ de biodigestor e as taxas de remoção de carga orgânica.

A determinação da série de sólidos ocorreu de acordo com os métodos estabelecidos pela APHA (1995), sendo o método 2540-B correspondente aos sólidos totais e o 2540-E aos sólidos fixos e voláteis (CEPPA, 2014).

O procedimento consistiu em primeiramente levar os cadinhos ao forno mufla a $600{ }^{\circ} \mathrm{C}$ para calcinarem por um período de duas horas. Depois de retirados da mufla os mesmos foram esfriados em um dessecador e, após, pesados em balança analítica, encontrando-se o peso do cadinho vazio (P1).

Posteriormente, os cadinhos foram preenchidos (aproximadamente $4 / 5$ do seu volume total) com amostra natural de afluente ou efluente do biodigestor e, foram novamente pesados, encontrando-se o peso do cadinho vazio + amostra natural (P2). Em seguida, os cadinhos com as amostras foram levados para a estufa a 105 ○C por no mínimo 12 horas.

Após foram resfriados em dessecador e promoveu-se novamente a pesagem, encontrando-se o peso do cadinho vazio + amostra seca (P3). Após estes procedimentos, as amostras foram levadas novamente à mufla por um período de duas horas a $600{ }^{\circ} \mathrm{C}$, resfriadas em dessecador e pesadas, obtendo-se assim o valor do cadinho vazio + cinzas (P4).

Para obtenção dos resultados dos sólidos totais, voláteis e fixos, em gramas, foram feitos os seguintes cálculos:

Sólidos Totais $=\mathrm{P} 3-\mathrm{P} 1$

Sólidos Voláteis $=\mathrm{P} 3-\mathrm{P} 4$

Sólidos Fixos $($ cinzas $)=\mathrm{P} 4-\mathrm{P} 1$

Para tanto, os equipamentos utilizados foram os disponíveis nos Laboratórios de Solos, Alimentos e Cromatrografia da Fundação para o Desenvolvimento Científico e Tecnológico de Toledo - FUNTEC, situados no município de Toledo - PR.

O volume de biogás produzido foi quantificado através de um medidor de gás modelo $G$ 0,6 fabricado pela LAO Indústria. Projetado para medição de consumo doméstico de gás natural, GLP ou manufaturado, o equipamento é provido de um sistema de irreversibilidade, evitando a totalização da produção de gás no sentido 
contrário ao da instalação. Este volume foi registrado de forma contínua e a leitura feita diariamente, antes da alimentação do biodigestor.

O teor de $\mathrm{CH}_{4}$ presente no biogás produzido foi medido por um detector de gás portátil da marca Dräger X-am 7000, obtendo os dados por meio de sensores infravermelhos.

\section{RESULTADOS E DISCUSSÃO}

\subsection{Remoção de sólidos}

Os sólidos voláteis obtiveram média nos afluentes correspondente a 1,059 $\mathrm{Kg} / \mathrm{m}^{3}$, apresentando um desvio padrão médio de $0,231 \mathrm{Kg} / \mathrm{m}^{3}$, sendo que os valores mínimos e máximos registrados foram, respectivamente, 0,713 e 1,340 Kg/m³ de sólidos voláteis presentes no dejeto. Os efluentes apresentaram como valores de sólidos voláteis a média de $0,384 \mathrm{Kg} / \mathrm{m}^{3}$, com desvio padrão médio de $0,138 \mathrm{Kg} / \mathrm{m}^{3}$, sendo os valores mínimos e máximos registrados, respectivamente, 0,197 e 0,608 $\mathrm{Kg} / \mathrm{m}^{3}$.

Com base nesses valores, pode-se calcular a remoção dos sólidos voláteis por $\mathrm{m}^{3}$ do biodigestor. Este parâmetro teve como média o valor de $0,675 \mathrm{Kg} / \mathrm{m}^{3}$ de biodigestor, sendo o desvio padrão médio de $0,163 \mathrm{Kg} / \mathrm{m}^{3}$ de biodigestor, enquanto os valores mínimos e máximos encontrados foram, respectivamente, 0,479 e 0,933 por $\mathrm{Kg} / \mathrm{m}^{3}$ de biodigestor. Na Figura 1 está representado o comportamento, em tratamentos, dos sólidos voláteis dos afluentes e efluentes, com sua respectiva remoção.

Figura 1 - Quantidade de sólidos voláteis do afluente e efluente e a remoção dos sólidos voláteis

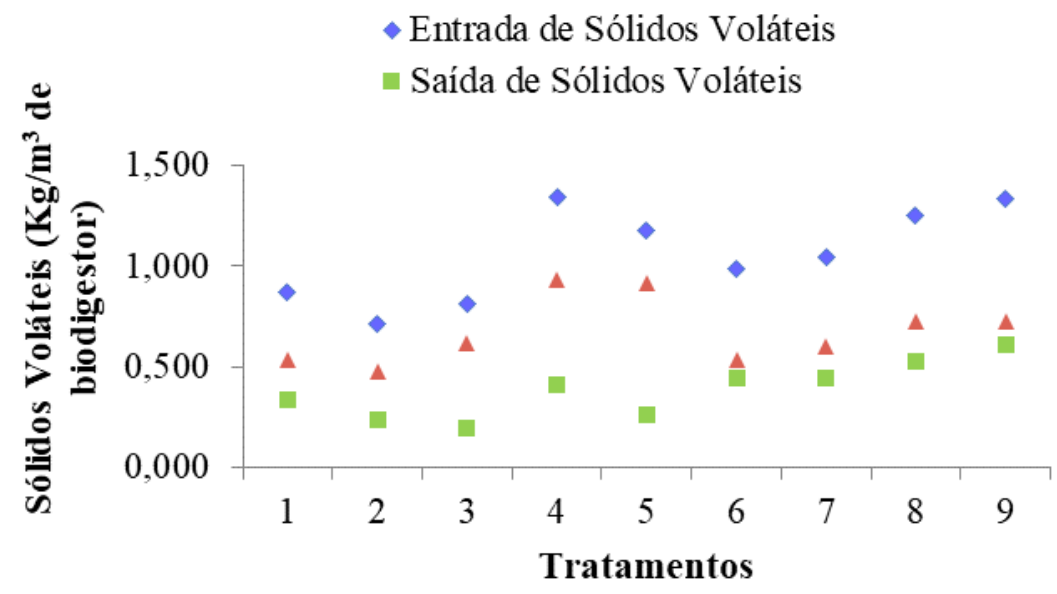


Colocando estes valores em termos de porcentagem, a remoção dos sólidos voláteis por $\mathrm{m}^{3}$ de biodigestor apresentou média de $63,76 \%$, com desvio padrão médio de $8,82 \%$, com valores mínimos e máximos de 53,84 e $77,44 \%$, respectivamente.

Leite e Povinelli (1999) estudaram o comportamento dos sólidos totais e voláteis no processo de biodigestão anaeróbia com resíduos sólidos urbanos e industriais, encontrando uma variação de remoção dos sólidos voláteis de 43,8 a 47,7\% (este número varia devido à heterogeneidade dos resíduos).

Mendonça (2009), que estudou o tratamento anaeróbico de efluentes de bovinocultura de leite, encontrou remoções de sólidos voláteis de 30,2 a $86,3 \%$, estes valores foram variáveis de acordo com o tempo de detenção hidráulica. Amaral et al. (2004) obtiveram redução de sólidos voláteis de 26,42 à $40,64 \%$, com média de $34,29 \%$. Já Orrico Junior et al. (2010) em estudo com cama de aviário em diferentes biodigestores, obtiveram uma média de $44,05 \%$ de retirada de sólidos voláteis.

Weber et al. (2014), estudando a biodigestão de bovinos de leite obtiveram um valor médio de redução de sólidos voláteis de $55,10 \%$, com desvio padrão médio de 19,23\%, com valores mínimos e máximos de 8,02 e 82,01\%, respectivamente.

Blanco et al. (2014), ao analisarem a produção de biogás a partir de dejetos da bovinocultura e cama de aviário em um biodigestor modelo Bioköhler alcançaram uma média de $64,23 \%$ de redução dos sólidos voláteis, sendo o desvio padrão médio de $10,76 \%$ e os valores de máximo e mínimo, respectivamente, de 84,99 e $49,84 \%$.

Sendo assim, pode-se afirmar que os dejetos de bovinocultura de leite neste experimento apresentaram remoção de sólidos voláteis superior ou permaneceram dentro da faixa de variação obtida pelos autores citados. Tratando-se da remoção dos sólidos totais encontrou-se, em porcentagem, uma média de $56,76 \%$ por $\mathrm{m}^{3}$ de biodigestor. Comparando este dado com os obtidos por Zschornack (2013) e Farias et al. (2012), em seus estudos, os quais obtiveram uma remoção de sólidos totais de $35,35 \%$ e $47,63 \%$, respectivamente, observou-se que o presente trabalho atingiu uma remoção aceitável. 


\subsection{Densidade dos dejetos}

A densidade é o produto entre massa e volume. Os dejetos de entrada do biodigestor apresentaram média de densidade de $1,027 \mathrm{~g} / \mathrm{mL}$, sendo que os valores mínimo e máximo médio dos tratamentos registrados foram, respectivamente, 1,024 e 1,030 g/mL, apresentando desvio padrão de $0,002 \mathrm{~g} / \mathrm{mL}$. O valor médio deste parâmetro registrado para os dejetos de saída foi de aproximadamente $1,013 \mathrm{~g} / \mathrm{mL}$, tendo-se como valores mínimo e máximo médios 1,012 e 1,014 g/mL, respectivamente, com desvio padrão de $0,001 \mathrm{~g} / \mathrm{mL}$. Na Figura 2 observa-se tanto os dados médios de densidade dos afluentes, quanto dos efluentes do biodigestor para cada tratamento.

Figura 2 - Dados médios de densidade dos afluentes e efluentes do biodigestor para cada tratamento Afluentes Efluentes

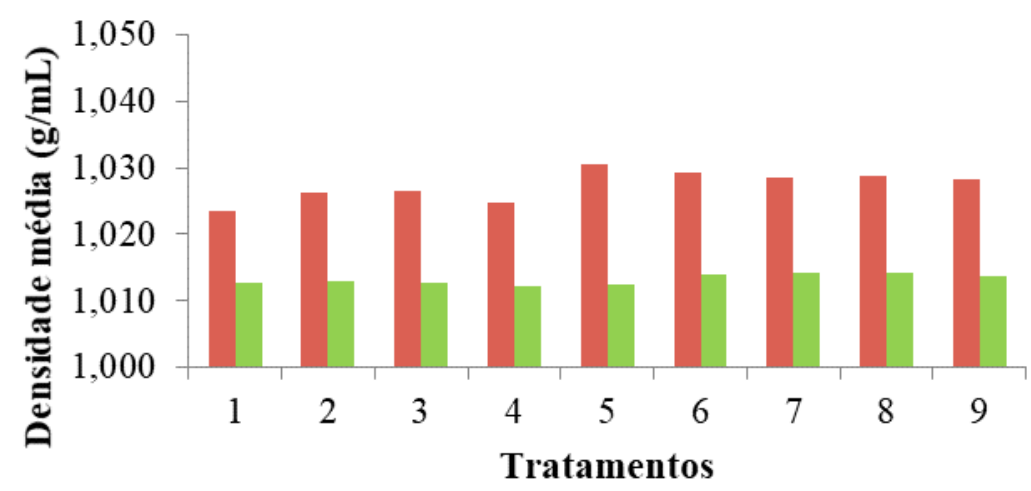

Pode-se verificar que a análise foi estável, não apresentando nenhuma variação significativa no período.

Averiguou-se uma diminuição deste parâmetro dos afluentes para os efluentes, portanto, pode-se deduzir que ocorreu uma redução da massa dos dejetos da saída, já que, segundo a equação da densidade, massa e densidade são proporcionais. Pode-se comprovar assim que a densidade diminuiu devido à remoção de sólidos da matéria, pois estes sólidos são a massa carbonácea do dejeto.

Weber et al. (2014) e Zschornack (2013), em seus estudos, também encontraram a densidade do afluente maior do que a do efluente do biodigestor em todos as semanas analisadas, comprovando assim que a densidade reduziu igualmente, em virtude da remoção de sólidos. 


\subsection{Produção de biogás}

A produção média de biogás foi de $11,771 \mathrm{~m}^{3}$, com a mínima de $9,613 \mathrm{~m}^{3}$ e a máxima chegando a uma produção de $13,961 \mathrm{~m}^{3}$, como é possível observar na Figura 3. O desvio padrão encontrado foi de $1,383 \mathrm{~m}^{3}$. Estes resultados foram superiores aos encontrados por Weber et al. (2014), que obtiveram uma média de produção de $3,408 \mathrm{~m}^{3}$ dia, no período de verão, alimentando o mesmo biodigestor também com dejetos bovinos e também aos dados obtidos por Zschornack (2013), o qual alcançou uma produção média de biogás de $4,63 \mathrm{~m}^{3}$, com a mínima de $0,018 \mathrm{~m}^{3}$ e a máxima de $8,92 \mathrm{~m}^{3}$, encontrando um desvio padrão de 2,10 $\mathrm{m}^{3}$, alimentando o biodigestor com dejetos bovinos e cama de aviário, no período de transição outono - inverno.

Já Blanco et al. (2014), que estudaram a biodigestão com dejetos bovinos, alcançaram uma produção média de biogás de $3,94 \mathrm{~m}^{3}$. O menor volume de biogás gerado foi de $0,018 \mathrm{~m}^{3}$ dia-1 e o maior foi de $6,809 \mathrm{~m}^{3}$ dia-1. O desvio padrão médio encontrado para o estudo foi de aproximadamente 1,26 $\mathrm{m}^{3}$.

Suzuki (2012), utilizando somente cama de aviário na alimentação do biodigestor, encontrou produção média diária de $3,928 \mathrm{~m}^{3}$ de biogás, sendo esta inferior à obtida nesse estudo.

Figura 3 - Produção média de biogás $\left(\mathrm{m}^{3}\right)$ por tratamento

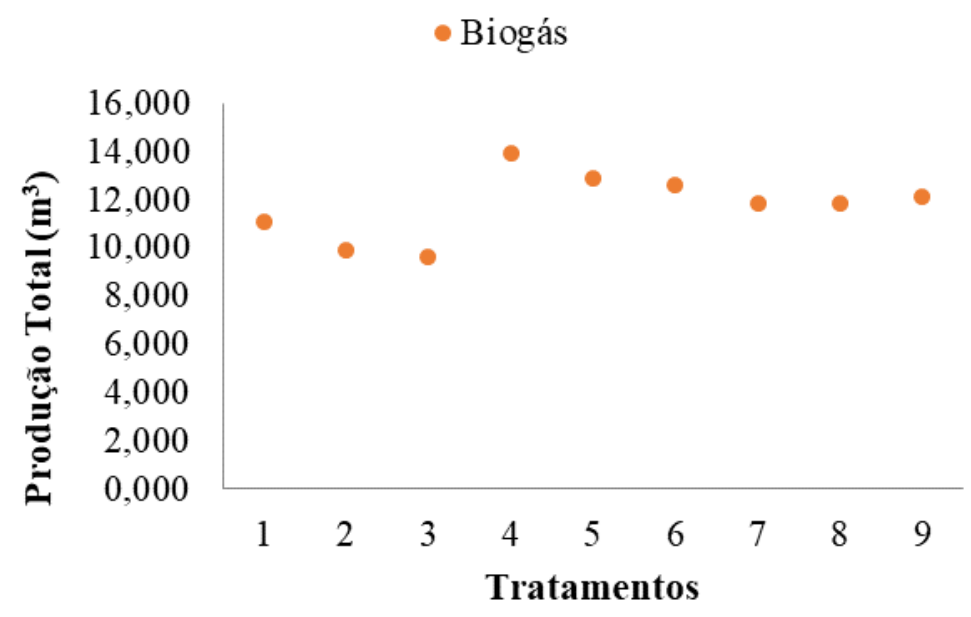




\subsection{Rendimento de biogás por ST e SV adicionados}

O valor médio de produção de biogás encontrado para sólidos totais e voláteis adicionados foram de 0,44 e 0,59 $\mathrm{m}^{3} / \mathrm{Kg}$, respectivamente. Esses valores são superiores aos encontrados por Suzuki (2012), o qual usou a cama de aviário como produto de alimentação do biodigestor, sendo $0,10 \mathrm{~m}^{3} / \mathrm{Kg}$ de sólidos totais e $0,13 \mathrm{~m}^{3} / \mathrm{Kg}$ de sólidos voláteis adicionados.

Em seu experimento Zschornack (2013) obteve 0,07 e $0,11 \mathrm{~m}^{3} / \mathrm{Kg}$ como valores médios de produção de biogás encontrados para sólidos totais e voláteis adicionados, respectivamente.

O mesmo foi observado nos dados obtidos por Feiden et al. (2004), os quais apresentaram valores médios de sólidos inferiores aos registrados neste estudo, 0,32 m³/Kg ST e 0,47 m³/Kg SV, utilizando águas residuárias da suinocultura.

\subsection{Rendimento de biogás por ST e SV removidos}

Para sólidos removidos, foram encontrados valores médios de 0,84 e 0,97 $\mathrm{m}^{3} / \mathrm{Kg}$ de sólidos totais e voláteis, respectivamente. Esses valores foram superiores aos encontrados por Suzuki (2012), os quais atingiram $0,14 \mathrm{~m}^{3} / \mathrm{Kg} \mathrm{ST}$ e $0,17 \mathrm{~m}^{3} / \mathrm{Kg}$ SV.

Zschornack (2013) alcançou valores médios de 0,21 e 0,25 m³/Kg de sólidos totais e voláteis, respectivamente.

\subsection{Produção de biogás por $\mathrm{m}^{3}$ de biodigestor}

Quando se considerou a produção específica média de biogás, o resultado obtido foi de 0,60 $\mathrm{m}^{3}$ de biogás por $\mathrm{m}^{3}$ de biodigestor. Feiden et al. (2004) obtiveram produção média diária de 0,298 $\mathrm{m}^{3}$ por $\mathrm{m}^{3}$ de biodigestor, com dejetos da suinocultura, sem agitação da biomassa, valor inferior ao registrado no presente trabalho. Weber et al. (2014) encontraram valor médio de $0,17 \mathrm{~m}^{3}$ de biogás por $\mathrm{m}^{3}$ de biodigestor, utilizando dejetos de bovinos leiteiros como fonte de alimentação.

Zhang et al. (1990), utilizando dejetos de suínos, obtiveram valor de 0,57 $\mathrm{m}^{3}$ por $\mathrm{m}^{3}$ de biodigestor, resultado próximo ao encontrado neste estudo. Suzuki (2012), 
utilizando somente cama de aviário na alimentação do biodigestor, encontrou 0,11 $\mathrm{m}^{3}$ de biogás por $\mathrm{m}^{3}$ de biodigestor.

\subsection{Produção de metano}

A produção média do gás metano encontrada no presente trabalho foi de 6,743 $\mathrm{m}^{3}$, com a mínima chegando a $5,643 \mathrm{~m}^{3}$ e a máxima, $7,971 \mathrm{~m}^{3}$ (Figura 4), tendo $0,777 \mathrm{~m}^{3}$ como o desvio padrão encontrado.

Figura 4 - Produção média de metano $\left(\mathrm{m}^{3}\right)$ por tratamento

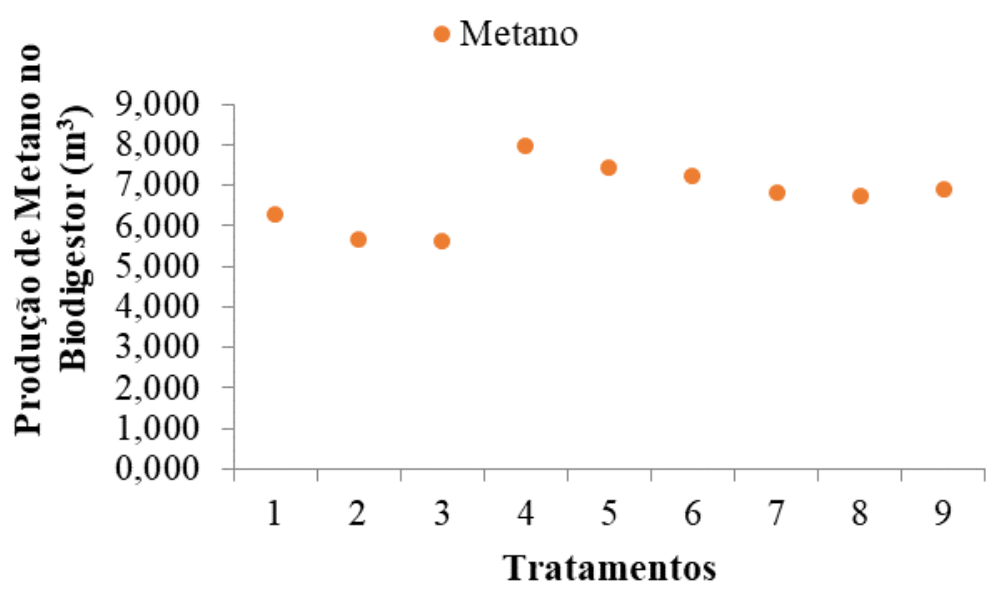

Analisando no biogás os valores de produção média de metano em termos de porcentagem, encontrou-se uma média de $57,33 \%$, com desvio padrão médio de 0,66\%, conforme se observa na Tabela 1 .

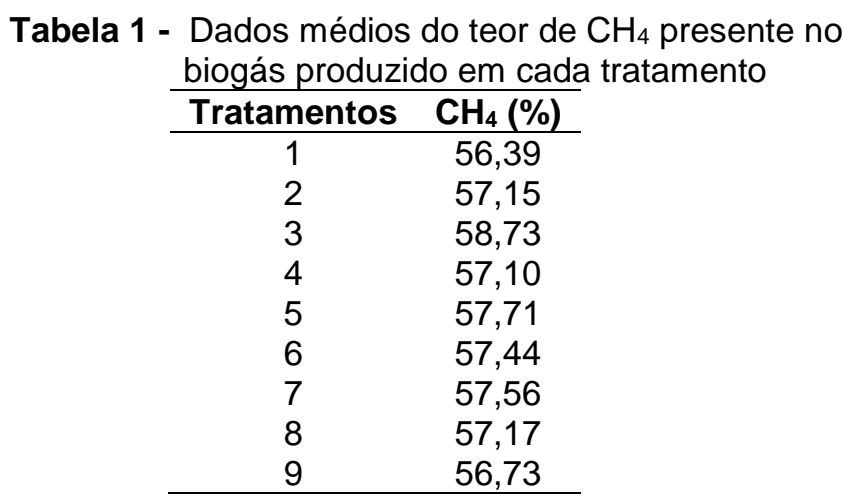

Com base nos dados presentes na Tabela 1, constatou-se que os teores de metano se mantiveram de acordo com a literatura, que segundo Faria (2012) e Castanón (2002), deve compreender seus valores entre 40-75\%. O maior teor foi obser- 
vado no $3^{\circ}$ tratamento, contando com $58,73 \%$ de $\mathrm{CH}_{4}$ e o menor foi de $56,39 \%$, no $1^{\circ}$ tratamento - uma diferença de $2,34 \%$.

\subsection{Rendimento de metano por ST e SV adicionados}

O rendimento de metano sobre os sólidos totais e sólidos voláteis adicionados apresentou valores médios de 0,25 e 0,34 $\mathrm{m}^{3} / \mathrm{Kg}$, respectivamente.

Já Suzuki (2012), alcançou valores inferiores, 0,05 e 0,07 m³/Kg de sólidos totais e voláteis adicionados.

\subsection{Rendimento de metano por ST e SV removidos}

Foram encontrados valores médios de 0,48 e $0,55 \mathrm{~m}^{3} / \mathrm{Kg}$ de rendimento de metano por sólidos totais e sólidos voláteis removidos, respectivamente.

Em seu experimento Suzuki (2012) obteve 0,08 e $0,09 \mathrm{~m}^{3} / \mathrm{Kg}$ de rendimento de metano por sólidos totais e voláteis removidos, respectivamente.

\subsection{Produção de metano por $\mathrm{m}^{3}$ de biodigestor}

Neste experimento foi obtida uma produção média específica de metano de 0,34 $\mathrm{m}^{3}$ por $\mathrm{m}^{3}$ de biodigestor, dado superior ao encontrado no trabalho desenvolvido por Suzuki (2012), o qual apresentou uma produção de $0,06 \mathrm{~m}^{3}$ por $\mathrm{m}^{3}$ de biodigestor.

\section{CONCLUSÕES}

A densidade dos efluentes quando comparada à dos afluentes apresentou uma diminuição da massa presente nos dejetos, indicando que houve remoção de sólidos, o que foi comprovado pelo balanço de massa.

A capacidade média esperada de produção de biogás manteve-se em torno de $12 \mathrm{~m}^{3}$ por dia, de acordo com a carga orgânica alimentada e as condições do experimento. 
Encontrou-se, em termos de porcentagem, uma média de 57,33\% de $\mathrm{CH}_{4}$ no biogás produzido, a qual está condizente com o proposto por diversos autores, situando-se na faixa especificada na literatura.

A remoção dos sólidos voláteis foi satisfatória, pois esta foi superior ou permaneceu dentro da faixa de variação obtida por outros autores.

\section{AGRADECIMENTOS}

À Coordenação de Aperfeiçoamento de Pessoal de Nível Superior (CAPES) pela bolsa concedida.

\section{REFERÊNCIAS}

AMARAL, C.M.C.; AMARAL, L.A.; LUCAS JUNIOR, J.; NASCIMENTO, A.A.; FERREIRA, D.S.; MACHADO, M.R.F. Biodigestão anaeróbia de dejetos de bovinos leiteiros submetidos a diferentes tempos de retenção hidráulica. Ciência Rural, v. 34, n. 6, p. 1897-1902, 2004.

ASSENHEIMER, A. Tratamento de dejetos bovinos em sistema intensivo de produção de leite com aeração mecânica. 2007. 93 f. Dissertação (Mestrado em Agronomia) - Universidade Estadual do Oeste do Paraná, Marechal Cândido Rondon, 2007.

BLANCO, M.F.J.; ZENATTI, D.C.; FEIDEN, A.; WEBER, R.; TIETZ, C.M.; GIACOBBO, G. Produção de biogás a partir de dejetos da bovinocultura de leite e cama de aviário. Acta Iguazu, Cascavel, v. 3, n. 1, p. 14-27, 2014.

CASTANÓN, N.J.B. Biogás, originado a partir dos rejeitos rurais. São Paulo: Universidade de São Paulo, 2002. 66 p.

CASTRO, L.R.; CORTEZ, L.A.B. Influência da temperatura no desempenho de biodigestores com esterco bovino. Revista Brasileira de Engenharia Agrícola e Ambiental, v. 2, n. 1, p. 97-102. 1998.

CEPPA - Centro de Pesquisa e Processamento de Alimentos. Universidade Federal do Paraná - UFPR. Laboratório: físico-química de água e efluentes. Curitiba, 2014.

CEPEA - Centro de Estudos Avançados em Economia Aplicada. Escola Superior de Agricultura "Luiz de Queiroz" - Esalq/Universidade de São Paulo - USP. Crescimento do setor suinícola é pautado na diversificação. Anuário 2017 da Revista Suinocultura Industrial, n. 06, ano 39, ed. 273. 2016.

Coordenação do sistema agroindustrial do leite é o maior desafio do setor. GRIGOL, N. 2018.

FARIA, R.A.P. Avaliação do potencial de geração de biogás e de produção de energia a partir da remoção da carga orgânica de uma estação de tratamento de esgoto - estudo de caso. 2012. 63 f. Dissertação (Mestrado em Energia na Agricultura) - Universidade Estadual do Oeste do Paraná, Cascavel, 2012. 
FARIAS, R.M.; ORRICO JUNIOR, M.A.P.; ORRICO, A.C.A.; GARCIA, R.G.; CENTURION, S.R.; FERNANDES, A.R.M. Biodigestão anaeróbia de dejetos de poedeiras coletados após diferentes períodos de acúmulo. Ciência Rural, Santa Maria, v. 42, n. 6, 2012.

FEIDEN, A.; REICHL, J.; SCHWAB, J.; SCHWAB, V. Avaliação da eficiência de um biodigestor tubular na produção de biogás a partir de águas residuárias de suinocultura. In: AGRENER GD 2004 - 5 Encontro de Energia no Meio Rural e Geração Distribuída. 2004. Anais... Campinas: Núcleo Interdisciplinar de Planejamento Energético da UNICAMP/NIPE. 2004.

IBGE - Instituto Brasileiro de Geografia e Estatística. Produção da pecuária municipal 2016, v. 44, 2017.

LEITE, V.D.; POVINELLI, J. Comportamento dos sólidos totais no processo de digestão anaeróbia de resíduos sólidos urbanos e industriais. Revista Brasileira de Engenharia Agrícola e Ambiental, v. 3, n. 2, p. 229-232, Campina Grande, 1999.

MENDONÇA, E.F. Tratamento anaeróbio de efluentes oriundos da bovinocultura de leite em biodigestor tubular. 2009. 62 f. Dissertação (Mestrado em Engenharia Agrícola) Universidade Estadual do Oeste do Paraná. Cascavel, 2009.

ORRICO JUNIOR, M.A.P.; ORRICO, A.C.A.; LUCAS JUNIOR, J. Influência da relação volumoso:concentrado e do tempo de retenção hidráulica sob a biodigestão anaeróbia de dejetos de bovinos. Engenharia Agrícola, Jaboticabal, v. 30, n. 3, p. 386-394, 2010.

PECORA, V.; FIGUEIREDO, N. J. V.; COELHO, S. T.; VELÁZQUEZ, S. M. S. G. Nota Técnica VIII - Biogás e o mercado de crédito de carbono. In: RIO OIL \& GAS EXPO AND CONFERENCE 2008, Rio de Janeiro. 2008.

SOUZA, C.F.; CAMPOS, J.A. Avaliação do tempo de retenção hidráulica, agitação e temperatura em biodigestores operando com dejetos de suínos. Revista Brasileira de Agroecologia, v. 2, n. 1, p. 1742-1745, 2007.

SUZUKI, A.B.P. Geração de biogás utilizando cama de aviário e manipueira. 2012. 60 f. Dissertação (Mestrado em Energia na Agricultura) - Universidade Estadual do Oeste do Paraná, Cascavel, 2012.

WEBER, R. ZENATTI, D.C.; FEIDEN, A.; TIETZ, C.M. Produção de biogás com relação ao teor de sólidos voláteis dos dejetos de bovinocultura de leite. Revista Brasileira de Energias Renováveis, v. 3, p. 43-55, 2014.

ZHANG, R.H.; NORTH, J.R.; DAY, D.L. Operation of a field scale anaerobic digester on a swine farm. Applied Engineering in Agriculture, St. Joseph, v. 6, n. 6, p. 771-776, 1990.

ZSCHORNACK, A.F. Balanço de massa de biodigestor modelo Biokohler alimentado com dejetos bovinos e cama de aviário no período de transição outono - inverno.

2013. 38 f. Trabalho de Conclusão de Curso (Graduação em Zootecnia) - Universidade Estadual do Oeste do Paraná, Marechal Cândido Rondon, 2013. 